\title{
Introducing Literature Critically and Creatively to Bangladeshi University Students
}

\author{
Nevin Farida E Begum Shahnaz Sinha
}

\begin{abstract}
In the National Curriculum for the Secondary and Higher Secondary levels in Bangladesh, there is hardly any focus on English literature in the English syllabus. Students who enter the English Department of Dhaka University face great difficulties in tackling literature. This paper aims to show how we meet the needs of our learners. We draw upon the techniques of close reading and stylistics to develop students' critical and creative abilities in order to respond to literature. This paper will also share some of the materials and activities used in the classroom by the teachers.
\end{abstract}

Key words: Literature, Teaching, Creative ability, Critical ability, University students

\section{Introduction}

This paper focuses on the problems faced by the first year students of the English Department, Dhaka University, while dealing with literary texts and shows how teachers help and deal with the needs of the students. The paper, therefore, attempts to: a) discuss how new techniques and materials are used by teachers and, b) show how literary texts can be used critically and creatively to Bangladeshi University students.

In Bangladesh, there was a change in the late 1980s in the English language
Curriculum in the Primary, Secondary and Higher Secondary levels. Communicative Language Teaching (CLT) instead of Grammar Translation Method (GTM) was introduced to develop students' linguistic competence. This new method brought a change in the textbook materials as well. All literary texts were dropped from the English syllabus. As a result, students who entered English Department felt great difficulties in tackling literature. These students lacked literary reading, foreign culture knowledge as well as appropriate linguistic competence. In order to help these novice 
students, a new course was introduced ('Critical Appreciation, Rhetoric and Prosody'). But since there were no appropriate textbooks for the course, the problem was aggravated and there was a very high rate of failure in this course. We along with some other teachers were part of the whole process, and were given the responsibility to address this grave problem. Consequently, we decided to develop new materials appropriate for our students' proficiency level and decided to change the teaching strategy. The paper, thus, includes our experiences with the new materials and new approaches to reading.

\section{Our aims in designing the new materials were to:}

- Help the students appreciate literature

- Help students identify figurative language

- Develop students' analytical ability so that they can critique texts independently

- Enhance students' imaginative awareness

- Facilitate them with foreign culture

- Make them aware of vocabulary used in English literature

- Familiarize students with foreign culture
As reading different types of literary texts played a significant role in our classes we decided to take a different approach to reading. Previously these classes were teacher centered and lecture based, where the teacher used to read and explain the texts and students just listened passively without taking any active role in the classroom. We decided to bring in some changes in our approach. Our new approach to reading was based on the views of different scholars.

\section{Approaches to reading}

Reading is widely viewed as an active process which requires processing the input. It is a process where a reader interacts with the text to find out the meaning. There are a number of approaches to develop reading. In this section our focus will be on some of these approaches. According to Krashen's (1985) Input Hypothesis, for language learning to occur, learners need to understand the input language which includes linguistic items that are usually beyond the learner's present linguistic competence. Nunan (1991) calls reading a 'top-down' process and gives importance to the reader's ability to predict his or her past experience and knowledge of the language. Rivers (1964), on the other hand, calls it a 'bottom-up' process and gives emphasis on decoding skills. While explaining the 'bottomup' process Carrell $(1988 \mathrm{a}, \mathrm{b})$ writes that reading is actually a decoding process of reconstructing the author's 
intended meaning by recognizing the smallest textual units at the bottom such as letters, and words to larger units at the top which are phrases, clauses, and sentences. Carrell (1988a) and Rumelhart (1977) have suggested that effective and efficient reading requires both 'top-down' and 'bottom-up' strategies working interactively. The interaction of the reader and the text is central to this process. Nunan (1991, p. 66), believes readers bring to this interaction "their knowledge of the subject at hand, knowledge of an expectation about how language works, motivation, interest, and attitude towards the content of the text." Stanovich (1980)claims that the interactive model is better than the other models because it deals with the shortcomings inherent in 'top-down' or 'bottom-up' models. Hedge (2000, p. 234) also thinks that the two processes are "mutually dependent and function simultaneously". She believes that in order to create comprehension and linguistic knowledge, contextual clues and prior knowledge must interact with one another. Harmer (2001, p. 201) expresses a similar view when he writes:

...it is probably most useful to see acts of reading... as interactions between top-down and bottom-up processing. Sometimes it is the individual details that help us understand the whole; sometimes it is our overview that allows us to process the detail.
According to Nuttall (2005), reading is a communicative process where the writer is an 'encoder' of a message which is received by a 'decoder'. The decoder's mind, however, cannot always receive or comprehend the entire intended message. This is when problems begin. For a successful communicative process, the writer and the reader must share several factors: they must share a code, that is, common language; they must possess a similar command of the language; they must share certain assumptions about the workings of the world. The last factor is where a schema theory comes into play which has a significant role in this study along with the other factors. The idea of 'decoding' the writer's message by the reader is also echoed in Papadima-Sophocleous's (2009) study aimed to motivate young students develop their reading skills using literature. Uysal (2012) citing Goodman (1992) argues from the socio-psycholinguistic point of view that readers' unfamiliarity with the content and textual organizational structure, as well as unfamiliar cultural elements in the text, cause problems in reading comprehension. Keeping these views in mind we tried to help our learners to become effective readers. We decided to follow the interactive approach while designing our materials. We also focused on close reading and intertextuality (Thornbury, 2005) which we felt would involve students more deeply into observing closely the text and evaluating them on their own. 


\section{Teaching method}

We decided to bring a change in our teaching methodology. Instead of the teacher centered method we decided to follow a learner-centered approach. Non-native speakers of English language function well in learner-centered classrooms where the teacher can come out of the traditional role of the all-knowing lecture giver and act as a facilitator and guide learners to act as active thinkers, not as 'empty vessels'. We also kept in mind that we have to make our students readers who love their texts, appreciate them and express a whole-hearted analysis of the texts (Young 2008). In order to use the literary texts we adapted the frameworks suggested by Maley (1989) and Talif (1994).

The proposed framework of Maley (as cited in Farida, 2001, 2003) was based on the three stages:

Framing : Getting ready

Focusing : Engaging

Diverging : Moving on

'Framing' is the warming up stage where students are made familiar with the thematic content of the text. In the 'Focusing' stage students are made to engage with the text through different language learning activities that lead them to understand and interpret the text. In the 'Diverging' stage the text is used as a "springboard to catapult the students elsewhere", that is, students are made to do follow-up activities like, role play, transfer to other text types, do creative writing etc. This framework is very similar to another effective framework proposed by Talif (1994, p. 122) designed for a Malaysian ESL context that shows how effectively literature can be used in the classrooms. This framework has been used by Farida $(2001,2003)$ in her studies on using literature with Bangladeshi EFL students studying University English in the department of English. Talif's (1994) framework for using literature in ESL instruction includes the following stages:

\section{The initial stage: Preparing students for the literary text}

- To initiate preliminary work to stimulate interest and motivation in preparing the students for the literary texts.

\section{The Middle Stage: Exploring the literary text}

- Pre-reading: to introduce students to understand the language and content of the literary text.

- During-reading: to assist students to understand the language and content of the literary text. 
- Post-reading: to determine the student understanding of the text; review and consolidation exercises.

\section{The final stage: Extension beyond the literary text}

- To stimulate further understanding of the literary text through the use of supplementary reading materials and exercises and follow-up activities.

While designing the materials we tried to cover all three genres and emphasized close-reading, and we divided each lesson into pre-, while, and post- stages. Extracts from poetry, prose and drama were selected mainly from the canonical British and American texts. We wanted our students, who mostly came from remote rural areas, to familiarize themselves with the famous names of the English literary world. A new item that we included in each unit of the book was the colorful western painting to stimulate interest and imagination of the learners, which, we believe can play a significant role in building our students' cultural context schemata, and help text comprehension and interpretation (Malik, 1990; Razi, 2004).

\section{The three-stage unit}

Following Talif's (1994) framework, we decided to divide our units (or lessons) into three stages: pre('Framing'), while- ('Focusing') and post- ('Diverging'). To show how we designed the materials and used it in the classroom at this point of the paper we would like to give an example of a unit. The unit presented in this paper focuses on the elements of 'setting'. It includes two poems and two excerpts from prose. The two poems, 'Landscape with the Fall of Icarus', by Williams Carlos Williams, and 'Fall of Icarus: Bruegel', by Joseph Langland are based on a painting by Peter Bruegel entitled Landscape with the Fall of Icarus (See Appendices 1-3) The title of the unit is 'Brushes and Pens'.

\section{The pre-stage}

At the very beginning of the lesson we decided to show our learners the painting by Bruegel (see Appendix1). Then they were asked to make a list of words which they think can be related to the painting. The lists were compared and the words were written on board to involve the whole class. After that students were asked some leading questions on:

- the title of the painting and the title of the unit

- the connection between the two words Brushes and Pens 
- what they think the unit is about, and what they may learn in this unit

- Icarus and Bruegel

- the activities visible in the painting

Carter and Long (1991) mentioned that the pre-reading activities can be very effective in getting students involved and motivating them before beginning the lesson. Our aim in the pre-stage was to activate the students' schemata. Carrel (1988b, p. 245) proposes a few ways in which relevant schemata may be built, such as lectures, visual aids, demonstrations, real-life experiences, discussion, role-play, text previewing, introduction and discussion of key vocabulary. We wanted to acquaint our students with Western art and culture, raise their interest and stimulate their imagination. We believed that the questions in this section will prepare the students and help them to understand the poems they will read later. At this stage, we decided to act as resource persons and gave information on the myth of Icarus. Students learnt about Icarus, how he tried to fly out of a country with the help of artificial wings; also how Icarus flew too near the sun and the wax of his wings melted and he fell and drowned. Information was also given by the teacher on Bruegel to help the students to understand and interpret the painting. Following the interactive model, at this stage we also provided the students a glossary of difficult words, helped with word meanings, and sentence structures, which we felt would make the texts easier and more comprehensible for the students. Studies done by Pearson-Casanave (1984), Chen and Graves (1995) and Grabe (2004) also support this view.

\section{The while-stage}

We divided the while stage into two sections: (a) Reading to understand the text and, (b) Reading for deeper level understanding or for critical reading. In the first section of the while-stage the students were given the texts (here, two poems; see Appendix $2 a$ and $2 b$ ) and were encouraged to read them closely. The teacher here acted as a facilitator. The teacher helped the students to understand the poems by giving word meanings and explaining difficult lines. The focus here was on simple paraphrasing. The aim of this stage was to understand the text and its vocabularies and be able to answer textual questions. To check whether students were able to comprehend the meaning and content of the two poems at this stage they were asked questions on:

- the language of the poems

- the protagonist

- protagonist's life

- what happened to him 
- the place where the incident took place

- the season

- the day

- the people mentioned in the second poem and what they were doing

- the different stanzas

- difficult phrases and expressions

These questions required students to read the text closely and carefully and give answers with specific information. Some of the questions required brief answers whereas some others needed detailed information.

Once students became familiar with the textual meaning, they were asked again to read the texts, either independently or in pair or in groups. In this later stage, teachers helped students by explaining the figurative devices. The focus then was on literary language, critical understanding, and thorough reading, so that the students could give personal and analytical responses with logic and reason. Since this unit focuses on setting, teachers explained what setting is and what role it plays in literary texts. For example, to help our students we provided the following information on setting:

\section{Setting}

In literary works, descriptions of places, atmosphere, things, and background form the setting of each work. Setting has many uses. Such as: - It may create a period of time. It may help to develop a character. ' It may be used to develop the theme. It may help to create the atmosphere, mood, and tone of a work. It may bring realism into a work by creating a recognizable location. ' Setting helps by giving information about the time and period of the action.

After they read the poems for the second time and once the literary devices were identified and explained by the teacher, students were given questions which required them to be analytical and critical in their responses. At this point they were asked questions on:

- the setting, and different elements that help to create the setting in the two poems

- the major focus in the poem ( fall/activities/indifference)

- words and phrases which show the indifference of others towards Icarus

- the tone of the two poems, their differences

- details which help to create the setting 
- the role of the setting in creating tone and mood

- the images used in the poems

- the difficulty level of language in the two poems

- the poem they find easier to follow; reasons for that

- the poem they liked more, and why

Thus, in this stage students were encouraged to explore and analyze the literary text, to read between the lines, identify literary devices, interpret the cultural issues and give personal opinions. Our learners were never encouraged before to think critically, analyze a text, or to give their responses in a class as the classes were not interactive. This new approach made classes more lively and interesting.

\section{The post stage}

In the final stage, we wanted our students to be creative as well as critical. We wanted to find out whether they could transfer their training or not. We gave them some excerpts (See Appendix 3a, 3b, 3c) to read and asked them to work in groups and discuss the different settings in these excerpts. After the discussion we asked them to work individually at home and write the answers to the questions which were based on the excerpts.
At this stage they were asked to reflect on:

- the three settings, to find out which one is easier to understand? Why?

- the places described here

- the character of Mr. Heathcliff from the description of the setting

- which description would make it easier for them to paint a picture of these two places and why?

- settings that they have come across in literary texts or paintings from Bangladeshi context

We found out that our learners do and can reflect, and they also like to give their opinions if they are given chances. They can also use their critical faculties and be creative if they are guided properly. Similarly, Papadima-Sophocleous (2009) has shown in her study that students enjoy reflecting and sharing their own experiences emotionally and intellectually with what they read in the literary texts. She also adds that this fosters students' critical thinking, and communicative skills as well as social practice. And as the language of literature possesses 'density of meaning', students can come up with different types of interpretations and new dimensions of perceptions as they work with those literary texts (Collie and Slater,1987; Scott, 2001). 


\section{Conclusion}

In this paper, we made an attempt to show how the materials we designed help students analyze the distinguishing features of literary language and allow students to participate in literary appreciation of English Literature, not just as passive readers but also as active readers who can enjoy, reflect as well as critique texts. Since our students come with limited experience of English literature reading, it was challenging to expect the same students to read in a new critical way and prepare them for graduate study in the English department. The 3stage units with several texts seem appropriate for both small group study and whole class work. The teachers using the activities/ questions initiate and develop discussion as starting points to explore the texts and experiences in them which later can be used for individual study.

As teachers teaching this course it is our privilege also to share some of the experiences that we gathered. Just after one year of running this pilot project, we noticed a great change among the students. They were very interested in the course, which was directly expressed by the students in their viva-voce when asked which course was their favorite. Their grades in the course improved rapidly. There were hardly any students in the consecutive years sitting for an improvement in that course. It seems that we as teachers have been able, even if partially, to help students get sensitized to the finer nuances of literature and develop some critical and creative abilities. We feel that new materials and teaching technique focusing on close reading, reader response, and cross-cultural comparison (Charles, 2011) can help learners in better understanding and interpretations of literary texts. We also believe that this course has to a certain extent addressed the problems for enabling students to understand literary texts that they are reading in other core literature courses in their syllabus, by enhancing learners' creativity and their ability to think critically.

\section{About the authors}

Nevin Farida is currently a Professor in the Department of English, University of Dhaka. She completed her MA in English Literature (DU) and M.Ed. in TESOL (Monash). She was awarded PhD in Applied Linguistics and ELT from Warwick University. Her research involved textual and contextual analysis of written English. Her areas of interest are materials development and the interface between literature and language teaching

Begum Shahnaz Sinha is a professor at the Department of English, University of Dhaka. She completed her B.A. (Honours) in English Literature and M.A. in Applied Linguistics and ELT from University of Dhaka. She has a second Masters in ELT from University of Warwick, UK. Her areas of interest include material development, discourse analysis, language planning and policy. 


\section{References list}

Carrell, P. L. (1988a).Some causes of textboundedness and schema interference in ESL reading. In Carrell, P. L., Devine, J. and Eskey, D. E. (Eds.), Interactive Approaches to Second Language Reading. Cambridge: Cambridge University Press.

Carrell, P. L. (1988b). Interactive text processing: Implications for ESL/ second language reading classrooms. In Carrell, P. L., Devine, J. and Eskey, D. E. (Eds.). Interactive Approaches to Second Language Reading. Cambridge: Cambridge University Press.

Carter, R. \& Long, M. (1991). Teaching literature. U.K.: Longman.

Charles, P. M. (2011). Reading the word and reading the world: Introducing extensive literature reading programs in Awassa College of Teacher Education and its partner schools. The Reading Matrix, 11 (3): 194-206.

Chen, H. C., \& Graves, M. F. (1995). Schema theory and ESL reading. TESOL Quarterly, 17 (4): 553-574.

Collie, J. \& Slater, S. (1987). Literature in the language classroom. Cambridge: CUP.

Farida, N. (2001). Images of doing university English through a literature-language subject in Bangladesh. Unpublished Master Thesis, Monash University, Australia.

Farida, N. (2003). Applying ELT methodology for literature classes in Bangladesh. Dhaka University Studies, Journal of the Faculty of Arts, 60 (2).

Goodman, K. S. (1992). Reading, writing, and written texts: A transactional sociopsycholinguistic view. Tucson, AZ: Literacy and Learning Center, University of Arizona.

Grabe, W. (2004). Research on teaching reading. Annual Review of Applied Linguistics, Vol. 24: 44-69.
Harmer, J. (2001).The practice of English language teaching. UK: Pearson Education Limited.

Hedge, T. (2000). Teaching and learning in the language classroom. Oxford: Oxford University Press.

Krashen, S.D.(1985).The input hypothesis: Issues and implications. London: Longman.

Maley, A. (1989). Down from the pedestal: Literature as resource. In Carter, Walker, Brumfit (Eds.), Literature and the Learner: Methodological approaches. ELT Documents 130: (10-24).

Malik, A.A. (1990). A psycholinguistic analysis of the reading behavior of EFL proficient readers using culturally familiar and culturally unfamiliar expository texts. American Educational Research Journal, 27 (1): 205-223.

Nunan, D. (1991). Language teaching methodology: A textbook for teachers. Prentice Hall International, Macmillan.

Nuttall, C. (2005). Teaching reading skills in a foreign language. UK: Macmillan Publishers Ltd.

Papadima-Sophocleous, S. (2009). Can teenagers be motivated to read literature? The Reading Matrix9 (2). Retrieved from http:// www.readingmatrix.com/articles/ april 2012/li chun.pdf

Pearson-Casanave, C.R. (1984).Communicative pre-reading activities: Schema theory in action. TESOL Quarterly,18 (2), 334-336.

Razi, S. (2004). The effects of cultural schema and reading activities on reading comprehension in M. Singhal \& J. Liontas (eds.). Proceedings of the First International Online Conference on Second and Foreign Language Teaching and Research. The Reading Matrix, Inc. US. Retrieved from http:// www.readingmatrix.com/conference/ $\mathrm{pp} /$ proceedings/razi.pdf 
Rivers, W. (1964). The Psychologist and foreign language teacher. Chicago: Chicago University Press.

Rumelhart, D. E.(1977).Toward an interactive model of reading. In Donic, S. (Ed.), Attention and Performance. Vol. 6: 573603. New York: Academic Press.

Scott, V. M. (2001). An applied linguist in the literature classroom. The French Review, 74 (3), 538-549.

Stanovich, K.E. (1980). Toward an interactive compensatory model of individual differences in the development of reading fluency. Reading Research Quarterly Vol 16 (1): 32-71.

Talif, R. (1994). Teaching literature in ESL: The Malaysian context. Kuala Lumpur: Penerbit Universiti Pertanian Malaysia.

Thornbury, S.( 2005). Beyond the sentence: Introducing discourse analysis. Oxford: Macmillan.

Uysal, H. H. (2012). Cross-cultural pragmatics of reading: The case of American and Turkish students reacting to a Turkish text. The Reading Matrix.Vol. 12 (1): 12-29.

Young, T. (2008). Studying English literature: A practical guide. Cambridge: CUP

\section{Appendix 1}

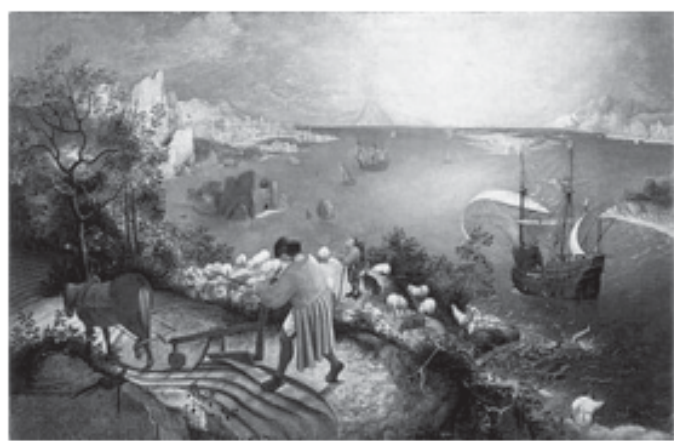

Peter Bruegel' Landscape with the Fall of Icarus (Image Under Creative Commons license from: http:/ / en.wikipedia.org/wiki/Icarus)

\section{Poem 1}

\section{Appendix 2}

\section{Landscape with the Fall of Icarus}

-William Carlos Williams (1883-1963)

According to Bruegel

When Icarus fell

It was spring
A farmer was ploughing his field the whole pageantry

of the year awake tingling near the edge of the sea concerned with itself

sweating in the sun that melted the wings'wax unsignificantly off the coast there was

a splash quite unnoticed this was Icarus drowning

\section{Poem 2}

\section{Fall of Icarus: Brueghel}

-Joseph Langland (1917-2007)

Flashing through fallen sunlight A frantic leg late plunging from its strange

Communicative moment

Flutters in shadowy waves.

Close by those shattered waters The spray, no doubt, struck shore- 
One dreamless shepherd and his old sheep dog

Define outrageous patience

Propped on staff and haunches, Intent on nothing, backs bowed against the sea,

While the slow flocks of sheep gnaw on the grass thin coast.

Crouched in crimson homespun an indifferent peasant

Guides his blunt plow through gravelled ground, Cutting flat furrows hugging this hump of land.

One partridge sits immobile on its bough

Watching a Flemish fisherman pursue

Fish in the darkening bay;

Their stillness mocks rude ripples rising and circling in.

Yet that was a stunning greeting For any old angler, peasant, or the grand ship's captain, Though sent by a mere boy Bewildered in the gravitational air, Flashing his wild white arms at the impassive sea-drowned sun.

Now only coastal winds

Ruffle the partridge feathers, Muting the soft ripping of sheep cropping,

The heavy whisper

Of furrows falling, ship cleaving, Water lapping.

Lulled in the loose furl and hum of infamous folly, Darkly, how silently, the cold sea suckles him.
Appendix 3

\section{Excerpt a}

1801 - I have just returned from a visit to my landlord- the solitary neighbor that I shall be troubled with. This is certainly a beautiful country! In all England, I do not believe that I could have fixed on a situation so completely removed from the stir of society. A perfect misanthrope's Heaven; and Mr. Heathcliff and I are such a suitable pair to divide the desolation between us.

\section{Excerptb}

Wuthering Heights is the name of Mr. Heathcliff's dwelling. 'Wuthering' being a significant provincial adjective, descriptive of the atmospheric tumult to which its station is exposed in stormy weather. Pure, bracing, ventilation they must have up there at all times, indeed; one may guess the power of the north wind blowing over the edge, by the excessive slant of a few stunted firs at the end of the house; and by a range of gaunt thorns all stretching their limbs one way, as if craving alms of the sun. (Wuthering Heights, Emily Bronte)

\section{Excerptc}

The scene: It is Central Park; a Sunday afternoon in summer, the present. There are two park benches, one toward either side of the stage; they both face the audience. Behind them; foliage, trees, sky. At the beginning, Peter is seated on one of the benches (Zoo Story. Edward Albee). 